\title{
Multiple sclerosis in the north Cambridgeshire districts of East Anglia
}

\author{
N Robertson, J Deans, M Fraser, D A S Compston
}

\begin{abstract}
The Cambridgeshire multiple sclerosis register was established in 1989 and initially reported a prevalence of $130 / 10^{5}$ population for south and east Cambridgeshire (south Cambs). This survey has now been extended to the northern county districts where there were 449 patients with multiple sclerosis in a population of 378959 on 1 July 1993 $\left(118 / 10^{5} ; 95 \%\right.$ confidence interval $(95 \%$ CI) 108-130). Four hundred and four had either definite or probable disease (107/105; 95\% CI: 98-118). This matches the highest figures in the series of seven epidemiological surveys carried out in southern England over the past decade. Comparison with these and other studies indicates that no latitudinal gradient of disease is found in southern England despite spanning four degrees of latitude.
\end{abstract}

$(\Im$ Neurol Neurosurg Psychiatry 1995;59:71-76)

Key words; multiple sclerosis, prevalence.

Multiple sclerosis is the commonest cause of neurological disability in young adults affecting at least 60000 people within the United Kingdom alone. It has been the subject of numerous epidemiological surveys reporting widely varying prevalence from $13 / 10^{5}$ in north Wales in $1929^{1}$ to $309 / 10^{5}$ in the Orkney Islands in $1974 .^{2}$ The studies in north east Scotland have been of particular interest, ${ }^{2-5}$ showing at one time the highest recorded prevalence figure and leading to the finding of a latitudinal gradient of disease within the United Kingdom which has given rise to a number of hypotheses for the disease aetiology. ${ }^{67}$ More recently, however, both the degree and the very presence of this gradient within the United Kingdom has been questioned $^{8} 9$ along with the validity of comparing studies that differ not only in population size but also in disease classification and methodology of ascertainment. In addition advances in medical care, information technology and trends in population dynamics have led to temporal changes in morbidity and mortality. Repeat studies in Scotland, 45 Northern Ireland, ${ }^{10}$ and southern England" have also found a trend of rising prevalence and it is not clear whether this represents a true increase in incidence or an artefact of improved case ascertainment. There exists, therefore a con- tinuing requirement for epidemiological studies, particularly in the heavily populated southern areas of England, with contemporary classifications of disease state and taking into account advances in laboratory investigations; these provide information for health service planning and allow the testing of aetiological hypotheses by comparing the frequency of multiple sclerosis in different populations.

The first epidemiological study of multiple sclerosis in East Anglia, performed in $1988^{12}$ reported a prevalence of $153 / 10^{5}$ for probable disease alone using the Allison and Millar criteria ${ }^{13}$ in five rural Suffolk practices, and confirmed East Anglia as a high prevalence area for the disease. As part of an ongoing study of the genetic epidemiology of multiple sclerosis, a prospective register of prevalent and incident cases was established in 1989 for patients seen in Cambridge; and a larger and more extensive study in the Cambridge Health District (south and east Cambridgeshire) in $1990^{14}$ reported a prevalence of $130 / 10^{5}$ for all classifications of disease using the Poser criteria. This survey has now been expanded to include the entire county of Cambridgeshire and includes data on the previously unsurveyed population of north Cambridgeshire.

\section{Study area}

Cambridgeshire is a land locked county lying in a predominantly rural region between latitudes 52 and 53 degrees north of the equator; it is bisected by the Greenwich meridian and covers an area of 339964 hectares. Its predominant geographical feature is of flat terrain with extensive fenlands to the north and east of the County. It is served by the North West Anglia and Cambridge and Huntingdonshire health commissions and separated into six county districts, three of which (Fenland, Peterborough, and Huntingdonshire) lie in the north of the county and represent the study area covering 179229 hectares. Neurological outpatient facilities are provided from district general hospitals in Peterborough and Huntingdon each served by two consultant neurologists and their staff, and all inpatient investigation is performed at a single regional neurology unit at Cambridge, where records are held for all patients seen since 1965 irrespective of domicile. The study area is served by 102 general practitioners operating from 61 surgeries, although some patients are registered with general practitioners outside the county boundaries. Population 
figures for the study area are published by the Cambridgeshire County Council Population Research Group, and report a 1991 midyear estimate of 378959 representing an increase of $12.9 \%$ since $1981 . .^{15}$ The average annual population growth rate for Cambridgeshire between 1981 and 1991 was $1.2 \%$ although this was higher during the first half of the decade. The settlement pattern of north Cambridgeshire is dominated by the city of Peterborough of which the urban area alone accounts for $37 \%$ of the population; other towns within the area include St Neots, St Ives, Wisbech, March and Huntingdon.

\section{Methods}

A provisional register was created from five sources that had previously been shown to be reliable in identifying patients for prevalence studies. All 32300 departmental notes were examined to identify patients seen 1965 in whom an established diagnosis of probable, definite, or suspected multiple sclerosis had been made. This was then matched to the existing register of prevalence for south Cambridgeshire, and the list of cases who were incident from 1990 . The preliminary register was entered into the Family Health Services Authority computer to identify those patients who were alive, resident in the study area, and currently registered with a general practitioner.

Four additional sources were used to identify patients with suspected or confirmed multiple sclerosis. All general practitioners within the Huntingdon and Peterborough county districts and adjoining areas were asked to provide names, addresses and dates of birth of affected patients registered with the practice and permission was sought to approach these patients. Reminders were sent at four monthly intervals to non-responding practitioners. Secondly, all local branch secretaries of the Multiple Sclerosis Society of Great Britain and Northern Ireland were asked to provide lists of affected members once permission had been obtained from the patients concerned. Thirdly, all nursing homes and facilities for the disabled were contacted to identify additional patients. Finally the computerised hospital database provided a list of those patients admitted with a primary or secondary diagnosis of multiple sclerosis to Peterborough hospitals since 1985; no such database existed for the Huntingdon hospitals. These last three sources were also entered into the Family Health Services Authority computer to confirm identification details and residence. Patients were considered prevalent if they were alive and normally resident in the area on 1 July 1993. All addresses were checked on a map displaying the county districts of Cambridgeshire published by Ordnance Survey. The methodology of case ascertainment therefore closely followed the original epidemiological study of south Cambridgeshire for 1990 .

After establishing that the patient was aware of the diagnosis and with consent from the general practitioner, attempts were made to contact all patients on the provisional register to collect clinical data and confirm residence within the study area. Where this was not possible, hospital or primary case notes were reviewed. Clinical classifications used the criteria both of Poser et al ${ }^{16}$ (where the upper limit of age of onset was ignored) and Allison and Millar ${ }^{13}$ so that comparison could be made with earlier studies; for the Poser criteria as in the original study, clinically definite multiple sclerosis, laboratory supported definite multiple sclerosis, clinically probable multiple sclerosis, and laboratory supported probable multiple sclerosis were collectively categorised as multiple sclerosis and distinguished from cases with suspected disease.

Age and sex specific prevalences were calculated as well as standardised prevalence ratios, based on the 1961 census population of Northern Ireland. ${ }^{17}$ Age at onset was defined as the year at which the first unequivocal neurological symptom of the disease had occurred; it was obtained directly from the patient where possible and if not from medical notes. Year of diagnosis was that recorded in the notes; if this was unavailable the patient's memory of events was accepted as evidence. Disability was assessed with the Kurtzke expanded disability status scale. ${ }^{18}$ Disease course recorded whether multiple sclerosis had been relapsing or progressive at onset as well as the time to second episode of neurological dysfunction where appropriate, and in the case of relapsing disease whether a secondary progressive course had supervened. Ninety five per cent confidence intervals (95\% CIs) were calculated as:

Upper limit $=$ (numerator/denominator measured in $\left.10^{5}\right) \times \mathrm{Z}$

Lower limit $=$ (numerator/denominator measured in $\left.10^{5}\right) / Z$,

where $Z$ is given as $\exp (1.96$ [square root of $1 /$ numerator).

Results are compared with other surveys using the Poser criteria - namely south Cambridgeshire, ${ }^{14}$ south east Wales, ${ }^{19}$ Southampton, ${ }^{20}$ Sutton, ${ }^{21}$ and more recently Mid Downs ${ }^{22}$ and the Channel Islands ${ }^{23}$ and $95 \%$ CIs were recalculated by the same methods. New diagnoses of multiple sclerosis made by Cambridge based neurologists for the study area were recorded prospectively on a central register. The study was approved by the local ethics cominittee and conformed with the requirements of the data protection act.

\section{Results}

The provisional register contained 563 patients from all sources, of which 324 were derived from departmental notes, 318 from general practitioner notifications, 85 from the Multiple Sclerosis Society, seven from residential facilities for the disabled, and 105 from the Peterborough hospitals database. Fifty eight of the 60 general practitioner practices responded to the request to participate in the study; one practice preferred not to supply information on the grounds of patient 
confidentiality and one small practice failed to respond to serial requests for information. One hundred (18\%) patients on the provisional register had either died, moved away from the area, were duplicate referrals, or it had become clear that an alternative diagnosis had been established, and these were all excluded. After further clinical evaluation based on personal interview or review of existing medical records, the diagnosis could not be confirmed in a further 13 patients; alternative diagnoses included adrenoleucodystrophy (one), functional illness (four), vasculitis (two), cervical myelopathy (one), Parkinson's disease (one), and the remainder had transient symptoms suggestive of neurological disease but an absence of clinical signs (four). Patients were also excluded if they had died before prevalence day or were not resident in the area as defined by the main address at which they were registered with their general practitioner. The final register therefore comprised 449 patients with multiple sclerosis, alive and prevalent within the study area on 1 July 1993 . The largest source for ascertainment of prevalent patients was

Table 1 Initial identification sources of prevalent patients in multiple sclerosis

\begin{tabular}{lcc}
\hline Source & All $n(\%)$ & Sole source $n(\%)$ \\
\hline General practitioners & $299(67)$ & $112(25)$ \\
Department notes & $252(56)$ & $98(22)$ \\
Hospital database & $83(18)$ & $21(5)$ \\
Multiple Sclerosis Society & $81(18)$ & $8(2)$ \\
Nursing homes & $5(1)$ & $0(0)$ \\
Total & & $239(54)$ \\
\hline
\end{tabular}

Table 2 Diagnostic classification of prevalent patients

\begin{tabular}{lcc}
\hline & No (\%) & Prevalence (95\% CI) \\
\hline Clinically definite & \multicolumn{1}{c}{ Poser classification } \\
Laboratory supported definite & $286(63 \cdot 7)$ & $75(70-88)$ \\
Clinically probable & $23(5 \cdot 1)$ & $6(4-9)$ \\
Laboratory supported probable & $75(16 \cdot 7)$ & $20(16-26)$ \\
MS? classification & $4(0 \cdot 9)$ & $1(0-3)$ \\
Suspected & $13(3 \cdot 0)$ & $3(2-6)$ \\
Total & $48(10 \cdot 7)$ & $13(9-16)$ \\
& $449(100)$ & $118(108-130)$ \\
Probable/early & \multicolumn{2}{c}{ Allison and Millar } \\
Possible & $376(83 \cdot 7)$ & $99(90-110)$ \\
Total & $73(16 \cdot 3)$ & $19(15-24)$ \\
\hline
\end{tabular}

MS ? classification = definite or probable multiple sclerosis (unverified). from general practitioner referrals (table 1) which identified $299 \quad(67 \%)$ patients. Departmental notes provided for $252(56 \%)$, the Multiple Sclerosis Society 81 (18\%), the hospital database $83(18 \%)$ and nursing homes $5(1 \%)$. Of the $239(53 \%)$ patients notified from a single source, $112(25 \%)$ were derived from general practitioner records, 98 $(22 \%)$ from departmental notes, $8(2 \%)$ from the membership lists of the Multiple Sclerosis Society, and 21 (5\%) from the hospital database. No patients were notified solely from nursing homes or residential facilities for the disabled. Two hundred and ninety one $(65 \%)$ of the 449 prevalent patients were examined or interviewed; $62(14 \%)$ either declined to take part or access was denied by their general practitioner; six had died and $96(21 \%)$ were too ill, had moved out of the area, or failed to respond to serial requests for contact.

Table 2 shows the diagnostic classification of the 449 prevalent patients. The prevalence of multiple sclerosis in north Cambridgeshire on 1 July 1993 was $449 / 379000$ population (118/105; 95\% CI 108-130). The standardised prevalence ratio calculated from the 1961 census population of Northern Ireland was $139 / 10^{5}$ (95\% CI 127-151). Two hundred and eighty six $(64 \%)$ had clinically definite disease, 23 (5\%) laboratory supported definite disease, $75(17 \%)$ clinically probable disease, four (1\%) laboratory supported probable disease, and $48(11 \%)$ suspected multiple sclerosis. Using the Allison and Millar criteria there were $376(84 \%)$ with probable and $73(16 \%)$ with possible disease (table 3 ). The figure shows the age and sex specific prevalence of multiple sclerosis in north Cambridgeshire, which varies from $1 / 10^{5}$ in the $0-14$ years age group (boys $0 / 10^{5}$, girls $1 / 10^{5}$ ) to $301 / 10^{5}$ (men 222/105; women $383 / 10^{5}$ ) in the $45-54$ age group. The sex ratio of females to males was $2 \cdot 2$. The mean age of prevalent patients was 50.0 (males 49.4, females $50 \cdot 3$, range $8-84$ ) years; mean age at onset was 33.8 (males $33 \cdot 1$, females $34 \cdot 1$, range $8-65$ ) years and mean age at diagnosis was 36.5 (range $8-84$ years). Two patients had disease onset over the age of 60 . Mean duration of disease was $16 \cdot 5$ (range 0-52) years from which a crude estimate of mean life expectancy of 33.0 years can be made based on twice the mean disease

Table 3 Comparison of United Kingdom surveys performed over the past 10 years with the Poser diagnostic classification

\begin{tabular}{|c|c|c|c|c|c|c|c|c|}
\hline & $\begin{array}{l}\text { SE Wales } \\
1985\end{array}$ & $\begin{array}{l}\text { Sutton } \\
1985\end{array}$ & $\begin{array}{l}\text { Southampton } \\
1987\end{array}$ & $\begin{array}{l}\text { S Cambridgeshire } \\
1990\end{array}$ & $\begin{array}{l}\text { Fersey } \\
1991\end{array}$ & $\begin{array}{l}\text { Guernsey } \\
1991\end{array}$ & $\begin{array}{l}\text { Sussex } \\
1991\end{array}$ & $\begin{array}{l}\text { N Cambridgeshire } \\
1993\end{array}$ \\
\hline $\begin{array}{l}\text { Population } \\
\text { Number of cases } \\
\text { Prevalence per } 10^{5}: \text { All } \\
\text { Prevalence per } 10^{5}: \text { MS } \\
\text { Mean age } \\
\text { Mean age at onset (y) } \\
\text { Mean disease duration (y) } \\
\text { Sex ratio } \\
\text { Incidence } \\
\text { SPR }\end{array}$ & $\begin{array}{l}376718 \\
441 \\
117(106-128) \\
101(91-112) \\
48 \cdot 7 \\
32 \cdot 2 \\
16 \cdot 5 \\
2 \cdot 0 \\
5 \cdot 4(1947-84) \\
139(126-150)\end{array}$ & $\begin{array}{l}170000 \\
195 \\
115(100-132) \\
104(89-120) \\
49 \cdot 0 \\
34 \cdot 1 \\
15 \cdot 4 \\
2 \cdot 3 \\
5(1974-84) \\
129(111-147)\end{array}$ & $\begin{array}{l}417000 \\
411 \\
99(89-109) \\
95(88-107) \\
48 \cdot 6 \\
32 \cdot 6 \\
15 \cdot 7 \\
2 \cdot 1 \\
4 \cdot 7(1976-82) \\
115(108-133)\end{array}$ & $\begin{array}{l}288410 \\
374 \\
130(117-144) \\
112(99-124) \\
49 \cdot 2 \\
29 \cdot 6 \\
19 \cdot 2 \\
2 \cdot 5 \\
5 \cdot 9(1989-91) \\
121(108-133)\end{array}$ & $\begin{array}{l}84042 \\
95 \\
\overline{100}(81-124) \\
53 \cdot 6 \\
- \\
-3 \cdot 1 \\
\overline{120}(96-144)\end{array}$ & $\begin{array}{l}61164 \\
53 \\
\overline{74}(55-99) \\
49 \cdot 6 \\
\overline{-} \\
\frac{2}{96}(70-121)\end{array}$ & $\begin{array}{l}596594 \\
665 \\
-111(103-120) \\
48 \cdot 6 \\
33 \cdot 1 \\
15 \cdot 5 \\
2 \cdot 5 \\
5 \cdot 0(1978-84) \\
-\end{array}$ & $\begin{array}{l}378959 \\
449 \\
118(108-130) \\
107(98-118) \\
50 \cdot 0 \\
33 \cdot 8 \\
16 \cdot 5 \\
2 \cdot 2 \\
6 \cdot 2(1990-93) \\
139(127-151)\end{array}$ \\
\hline
\end{tabular}

*Standardised prevalence ratio calculated from Allison and Millar criteria and based on the 1961 census population of Northern Ireland. All $=$ definite, probable, and suspected multiple sclerosis; MS = definite and probable multiple sclerosis only; figures in parentheses are $95 \%$ CI. 
Cambridgeshire multiple sclerosis register: north Cambridgeshire age and sex specific prevalence.

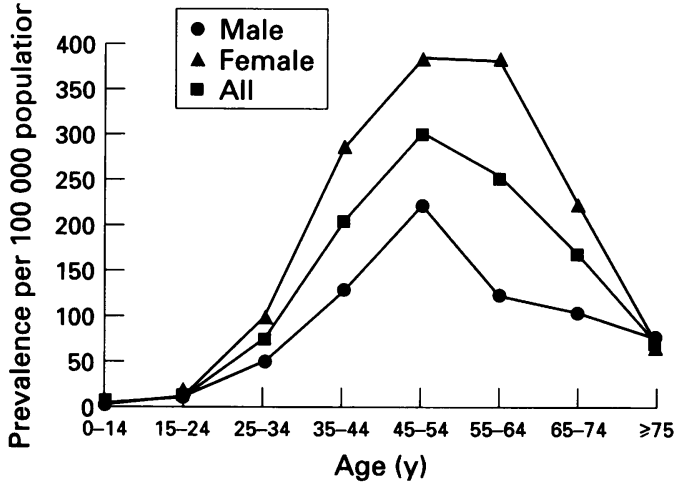

duration according to Poskanzer's method. Kurtzke disability scale status was available on $234(52 \%)$ of patients. The age of onset, disease duration, clinical classification, and sex distribution did not differ significantly in this cohort from the prevalent population as a whole. Mean disability was $5 \cdot 0$. According to the classification of severity of disease suggested by the European Database for Multiple Sclerosis, ${ }^{24}$ Five $(2 \%)$ had a hyperacute form of disease, $11(5 \%)$ had an acute form, 17 $(7 \%)$ a subacute form, $68(29 \%)$ an intermediate form, $12(5 \%)$ a benign form and 121 $(52 \%)$ had a non-assessable form. Of those patients in whom a disease course from onset could be defined 84 (22\%) had progressive disease from onset and $289(78 \%)$ relapsing disease of which 85 (29\%) had become secondarily progressive; six of the 48 patients with suspected disease had progressive and predominantly spinal disease. The commonest symptom at disease onset was limb sensory, followed by limb motor and optic neuritis. Five per cent of symptoms at onset suggested multiple sites and the mean time to second relapse for those patients with a relapsing course of disease was 3.4 years; $95 \%$ of patients with probable or definite disease had a second episode of neurological dysfunction within 10 years. Seventy eight $(17 \cdot 4 \%)$ patients reported an additionally affected relative; a detailed analysis of the recurrence risk for multiple sclerosis in relatives of prevalent patients from East Anglia is in preparation.

According to mid-1991 estimates ${ }^{1} 15500$ $(4 \cdot 1 \%)$ persons in north Cambridgeshire described themselves as belonging to an ethnic group other than white ${ }^{25}$; this frequency varied from $0.8 \%$ in Fenland to $7.5 \%$ in Peterborough district. Four of the 449 prevalent patients $(1 \%)$ were of non-white origin; two were Asians, one Mauritian, and one Afrocaribbean. Two had white ancestry; three were British born and one (the Mauritian) had moved to Britain at the age of 14 . The prevalence in the white population of north Cambridgeshire was therefore 445/364000 $\left(122 / 10^{5} ; 95 \%\right.$ CI $\left.111-134\right)$ and in the ethnic minority population 4/15 $500\left(26 / 10^{5}\right.$; $95 \%$ CI 10-69). It is of interest that affected people from ethnic minorities were restricted to those from white ancestry or immigrating at a young age, and is in keeping with the pattern of low prevalence in Asian and Caribbean immigrants in contrast with the relatively high prevalence in United Kingdom born children of these immigrants in the age groups available for study that has previously been reported. ${ }^{26}$ Merging data from this study with that from the survey of south Cambridgeshire in 1990 results in combined prevalence for the county of Cambridgeshire of $123 / 10^{5}(95 \%$ CI 115-132).

Between January 1990 and December 1995 Cambridge based neurologists made 284 new diagnoses of multiple sclerosis, of which 92 lived within the study area (73 probable or definite, 19 suspected); this provides a crude incidence of $6 \cdot 1 / 10^{5} /$ year population $\left(4 \cdot 8 / 10^{5}\right.$ probable/definite cases only).

\section{Discussion}

This study is the second major epidemiological study of multiple sclerosis in the East Anglian region of England and the seventh in a series carried out in the southern half of the country over the past 10 years with comparable methodology and clinical classification ${ }^{14}$ 19-21 23 (table 3). Prevalence matches the highest figures for the large region of southern England and Wales and although lower than the updated figure based on a reassessment of prevalence in $1993^{11}$ is not significantly different to that obtained in south Cambridgeshire in $1990 .{ }^{14}$ One of the striking features of all these studies is the similarity in clinical aspects of the disease including age and sex distribution, age at onset, disease course, disease duration and diagnostic classification. Of the seven studies that used the Poser criteria for clinical classification, the only statistical difference in regional prevalence, apart from Guernsey, which is difficult to interpret because of the small numbers, lies between Southampton (99; 95\% CI 89-109) and the 1990 survey of south and east Cambridgeshire $^{6}$ (130; 95\% CI 117-144), despite these surveys covering a geographical area separated by 4 degrees in latitude; a similar difference exists between the most northerly of these seven studies and north east Scotland. Direct comparison of published figures, however, may be misleading as prevalence in south Glamorgan, south Cambridgeshire, Sutton, and Southampton was estimated from all categories of multiple sclerosis whereas the Sussex, Jersey, and Guernsey studies report figures for definite or probable disease only, therefore the difference between surveys relies on interpretation of the "suspected" category, as comparison of prevalence for multiple sclerosis only shows no regional difference. ${ }^{9}$

Because the suspected group is of some importance in defining differences in prevalence within the United Kingdom it is necessary to examine the validity of including this group. The original Poser disease classification groups did not include a suspected category; however, in attempts to compare contemporary studies with those performed in the north east of Scotland and Northern 
Ireland, which used the Allison and Millar criteria, it became clear that a group equivalent to the possible category was needed. It was first used in the south Glamorgan study in 1985 and is now accepted as referring to those suspected of having demyelinating disease but without signs or paraclinical evidence for more than one lesion. In our population in whom disease course at onset and time to second episode could be established the median time to second relapse was 3.5 years and $95 \%$ had a second episode of dysfunction within 10 years. Forty two of 48 patients classified as suspected disease in our study had relapsing disease; of these, 10 (24\%) had their single episode of neurological dysfunction more than 10 years previously and so now seem less likely to develop further manifestations of disease that would move them to a firmer classification. In south Glamorgan the suspected category accounted for $60(14 \%)$ of the total number of prevalent patients; in south Cambridgeshire this was $54(14 \%)$ and in Southampton $16(4 \%)$; Sussex, Jersey, and Guernsey studies have not included suspected disease within their overall prevalence figures. The paucity of suspected cases in the Southampton study was noted by the authors who postulated that this may have resulted from the low proportion ascertained from departmental indices or from a regional diagnostic bias. For the present, all patients with suspected disease are included irrespective of the temporal relation to their symptoms, but care should be taken in future that apparent changes in prevalence are not simply the result of an increase in this suspected category, a substantial proportion of whom will not develop definite or probable disease. For this reason, publication of prevalence figures should clearly indicate whether they represent all disease classifications or simply definite and probable, the second being the more robust statistic. Once these points are taken into account, there exists an emerging pattern of stability in disease prevalence in the southern United Kingdom and a simple linear relation between latitude and prevalence within the United Kingdom now seems unlikely.

Because multiple sclerosis is more common in females and young adults, standardisation of the population to take account of differences in age and sex structure has been a popular method of examining differences in prevalence in United Kingdom studies and has universally used the 1961 population of Northern Ireland as standard. The effect has been to eliminate all significant difference in prevalence except those between the southern England studies and Aberdeen where the contemporary rate is the result of serial surveys. Despite widely quoted differences, however, in prevalence between certain ethnic minority groups and Caucasians, ${ }^{26-31}$ little attempt has been made either in or outside the United Kingdom to allow for the ethnic mix of the population under study. One exception is the study of multiple sclerosis in north and south New Zealand in $1981^{32}$ where quoted figures for prevalence exclude the Maori population.
Certainly there is a significant difference in ethnic mix between north and south Cambridgeshire, which accounts in part for the slight difference in prevalence; it would seem reasonable to quote that proportion of the population made up by ethnic minorities to ensure that this makes no significant difference to prevalence.

Other factors that may produce local differences in prevalence include the size of the population; smaller, well defined geographical areas may be expected to deliver a more complete case ascertainment and may explain some of the disproportionate increase in certain island populations. Other factors that introduce artefacts include the location of residential facilities for the disabled, distance from the regional neurological centre, disribution of general practitioners, and the role of serial studies. In Aberdeen, ${ }^{3} 33$ Shetland, and the Orkneys ${ }^{2}$ the prevalence for probable, definite, and possible disease according to the Allison and Millar criteria has increased with serial observations from $127 / 10^{5}$ (1970), $134 / 10^{5}$ (1954), and $111 / 10^{5}(1954)$, to $178 / 10^{5}$ (1980), $184 / 10^{5}$ (1974) and $309 / 10^{5}(1974)$ respectively. Results are more conflicting in southern England with no significant increase in prevalence between 1985 and 1988 in south Glamorgan ${ }^{34}$ but an increase from $130 / 10^{5}$ in 1990 to $152 / 10^{5}$ in 1993 in south Cambridgeshire. ${ }^{11}$ A multicentre incidence or prevalence study based on that performed in Australia in $1981^{35}$ has long been advocated, and now that a standardised method of data collection is a step closer with the wider acceptance of the European Database for Multiple Sclerosis ${ }^{24}$ the logistics of this study have become more realistic.

1 Allison RS. Disseminated sclerosis in North Wales. Brain 1931;53:391-430.

2 Poskanzer DC, Prenny LB, Sheridan J, Condy JW. Multiple sclerosis in the Orkney and Shetland Islands. 1: Epidemiology, clinical factors and methodology. 1: Epidemiol Community Health 1980;34:229-39.

3 Shepherd DI, Downie AW. Prevalence of multiple sclerosis in north-east Scotland. BMF 1978;2:314-6.

4 Shepherd DI, Downie AW. A further prevalence study of multiple sclerosis in north east Scotland. I Neurol Neurosurg Psychiatry 1980;43:310-5.

5 Downie AW, Phadke JG. The Chief Scientist reports. Multiple sclerosis in north east Scotland. Health Bull (Edinb) 1983;42:151-6.

6 Cook SE, Cromerty JI. Declining incidence of multiple sclerosis in the Orkney Islands. Neurology 1985;35: 545-51.

7 Swingler RI, Compston DAS. The distribution of multiple sclerosis in the United Kingdom. I Neurol Neurosurg Sclerosis in the United King
Psychiatry 1986;49:1115-24.

8 Compston DAS. The dissemination of multiple sclerosis. The Langdon Brown lecture. $\mathcal{F} R$ Coll Physicians (Lond) 1989;24:207-18.

9 Robertson NP, Compston DAS. Surveying multiple sclerosis in the United Kingdom. F Neurol Neurosurg Psychiatry 1995;58:2-6.

10 Hawkins SA, Kee F. Updated epidemiological studies of multiple sclerosis in Northern Ireland. $尹$ Neurol 1988; 235(suppl):S86.

11 Robertson NP, Fraser M, Deans J, Compston DAS. The Cambridgeshire multiple sclerosis register: three year update, incidence and mortality data. 7 Epidermiol Community Health 1995 (in press).

12 Lockyer M. Prevalence of multiple sclerosis in five rural Suffolk practices. BMF 1981;303:347-8.

13 Allison RS, Millar JHD. Prevalence and familial incidence of disseminated sclerosis (A report to the Northern of disseminated sclerosis (A report to the Northern
Ireland Hospitals Authority on the results of a three year
survey). Ulster Med 7 1954;23:5-27.

14 Mumford C], Fraser MB, Wood NW, Compston DAS. Multiple sclerosis in the Cambridge Health Authority. Multiple sclerosis in the Cambridge Health
$\mathcal{f}$ Neurol Neurosurg Psychiatry 1992;55:877-82. 
15 Cambridgeshire County Council Research Group Population forecasts 1989-2001. Cambridge: Cambridgeshire County Council 1992

16 Poser C, Paty D, Scheinberg L, et al. New diagnostic criteria for multiple sclerosis: guidelines for research protocols. Ann Neurol 1983;13:227-31.

17 Millar IHD. Multiple sclerosis in Northern Ireland. In: Clifford Rose F, ed. Clinical neuroepidemiolo

18 Kurtzke IF. Rating neurological impairment in multiple sclerosis: an expanded disability scale status. Neurology 1983;33:1444-52.

19 Swingler RI Compston DAS. The prevalence of multiple sclerosis in south east Wales. F Neurol Neurosurg Psychiatry 1988;51:1520-4.

20 Roberts MHW, Martin IP, McLellan DL, McIntoshMichaelis SA, Spackman AJ. The prevalence of multiple sclerosis in the Southampton and South West Hampshire Health Authority. F Neurol Neurosurg Psychiatry 1990;53:55-9.

21 Williams ES, McKeran RO. Prevalence of multiple sclerosis in a south London borough. Brit Med $\mathcal{F}$ 1978;293: 237-9.

22 Rice-Oxley M, Williams ES, Rees IR. A prevalent survey of multiple sclerosis in Sussex. I Neurol Neurosurg Psychiatry 1995;58:27-30.

23 Sharpe G, Price SE, Last A, Thompson RJ. Multiple sclerosis in island population prevalence in the Bailiwicks of rosis in island population prevalence in the Bailiwicks of
Guernsey and Jersey. $₹$ Neurol Neurosurg Psychiatry 1995; 58:22-6.

24 Confraveux C, Compston DAS, Hommes OR, MacDonald WI, Thompson AJ. EDMUS, a European database for multiple sclerosis. F Neurol Neurosurg Psychiatry 1992;55:671-6.
25 Cambridgeshire County Council Research Group. The 1991 census; The Local Picture Ethnic group report. Cambridge: Cambridgeshire County Council, 1994.

26 Elian $M$, Nightingale S, Dean $G$. Multiple sclerosis amongst United Kingdom-born children of immigrants from the Indian subcontinent. $f$ Neurol Neurosurg Psychiatry 1990;53:906-911.

27 Hoestler JA. The Hutterite Society. Baltimore: Iohn Hopkins University Press, 1974.

28 Hader WI, Fearty TE, Noseworthy JH, Rice GPA, Ebers GC. Multiple sclerosis in Canadian native people [abstract]. Neurology 1985;35(suppl):300.

29 Davenport CB. Multiple sclerosis from the standpoint of geographical distribution and race. Arch Neurol 1922; 8:51-8.

30 Elian M, Dean G. Multiple sclerosis amongst United Kingdom-born children of immigrants from the West

31 Dean G. Annual incidence and mortality of multiple sclerosis in white African-Born and in white immigrants to South Africa. BfM 1967;2:724-30.

32 Skegg CG, Corwin PA, Craven RS, Malloch JA, Pollack $M$. Occurrence of multiple sclerosis in the north and south of New Zealand. $\mathcal{F}$ Neurol Neurosurg Psychiatry 1987;50:134-9.

33 Phadke IG, Downie AW. Epidemiology of multiple sclerosis in north east (Grampian Region) of

34 Hennessy A, Swingler RI, Compston DAS. The incidence and mortality of multiple sclerosis in south east Wales. and Neurol Neurosurg Psychiatry 1989;52:1085-9.

35 Hammond SR, McLeod JG, Millingen KS, et al. The epidemiology of multiple sclerosis in three Australian cities: demiology of multiple sclerosis in three Australian cities: 